\title{
Freshwater fish diversity database of Central India: Implementation and utility
}

\author{
AJEY KUMAR PATHAK, UTTAM KUMAR SARKAR*, RAJESH DAYAL, REETA CHATURVEDI \\ AND RAVI KUMAR \\ ICAR-National Bureau of Fish Genetic Resources, Canal Ring Road, P.O. Dilkusha, Lucknow - 226012 \\ Uttar Pradesh, India \\ *ICAR-Central Inland Fisheries Research Institute, Barrackpore, Kolkata - 700 120, West Bengal, India \\ e-mail: pathakajey@gmail.com
}

\begin{abstract}
The modern relational database technologies provide reasonable approaches to address the biodiversity problems facilitating storage, efficient searches and retrieval of information about species of interest. This contribution focuses on development of a digital database to view fish and fisheries information using integrated tools. To address storing and reporting of information on the fish diversity of the central states of India, MS Access relational database management system for backend and Visual Basic technologies for frontend under Windows operating platform were used. Development of the database was essential to store the data compiled from various published sources; to provide information-oriented services as well as to keep the data up-to-date with the recent information. Presently, the database covers 208 species of fishes belonging to 13 orders, 35 families and 82 genera from Madhya Pradesh; 155 species belonging to 11 orders, 30 families and 81 genera from Rajasthan and 144 species belonging to 11 orders, 30 families and 85 genera from Chhattisgarh. The application features of the database includes search, query and action command button tools that provide ability for retrieving and viewing the information of interest from the database.
\end{abstract}

Keywords: Central India, Chhattisgarh, Database, Freshwater fish diversity, Madhya Pradesh, Rajasthan

\section{Introduction}

Worldwide, the freshwater ecosystems are the most endangered ecosystems (Sala et al., 2000) and these environments are facing threats with regard to ecosystem stability and biodiversity (Cowx, 2002; Suski and Cooke, 2006). The vulnerability of freshwater environment to fish at a global scale reflects the fact that both fish and freshwater are the need of humans and these have been heavily impacted by their use and regulation. In India, the freshwater ecosystems are one of the most exploited environs for many years for commercial purposes. The Central India comprising the states of Madhya Pradesh, Chhattisgarh and Rajasthan has diverse and numerous freshwater bodies in the form of streams, rivers, reservoirs, sub-terrain aquatic ecosystems, traditional lakes and domestic ponds that provide abode to wide variety of freshwater fishes. The Central India harbours nearly 166 indigenous freshwater fish species (Lakra and Sarkar, 2007) of food, sport and aquarium value from its vivid freshwater resources that accounts nearly $5.2 \%$ of the total native fish diversity of India and $18.6 \%$ to the native freshwater diversity of India. The conservation status assessment of 166 native freshwater fishes was carried out during the Conservation Assessment of Freshwater Fish for Central India (CAFF) organised in 2006 at the
ICAR-Central Institute of Agricultural Engineering, Bhopal, Madhya Pradesh, India in which ICAR-National Bureau of Fish Genetic Resources (ICAR-NBFGR), Lucknow, Uttar Pradesh, India was the nodal agency. The assessment revealed one species to be under critically endangered (CR), 28 under endangered (EN), 59 under vulnerable (VU), 99 under data deficient (DD), 87 under lower risk near threatened (LRnt) and 46 under lower risk least concern (LRlc) categories (Lakra and Sarkar, 2007). Thus, nearly $50 \%$ of the freshwater fish species of this region were assessed under the threatened category, which is an alarming situation for the freshwater fishes of this region. The fish diversity in any geographical region though determined by a number of factors, mainly depends on the geographical position, varied aquatic ecological conditions, health of aquatic bodies, optimum exploitation of the commercial fish species, enforcement of laws, implementation of rules and regulations and fish habitat restoration programmes (Uchchariya et al., 2012). The fish diversity includes both species and functional diversity. The species diversity is the property at the population level while functional diversity is more related to ecosystem stability and stresses, physical and chemical factors and plankton (Kar and Barbhuiya, 2004).

Fishes being the staple item in the diet of many people for nutritional security are one of the important elements 
in the economy of many nations (Talwar and Jhingran, 1991). Among all the vertebrate groups, fishes have the highest species diversity. Globally, more than 32,300 fish species have been reported (Froese and Pauly, 2018) and India contributes nearly 3,157 fish species out of which 892 species are purely freshwater inhabitants; 1,545 are purely marine and 17 are purely brackishwater species (NBFGR, 2020). According to a report, the Indian species represent around $8.9 \%$ of the known fish species of the world (Baker et al., 2008) and contributes about $11.72 \%$ of global fish diversity mainly from the greater Himalayan range on the northern plains, long stretches of Eastern and Western Ghats (Lakra et al., 2010) and is the third largest producer of fish in the world.

Currently, fish biodiversity loss is one of the world's most pressing crises, and besides other concerns, sustainable exploitation of fish stocks through increasing harvest pressure, destructive fishing operations and introduction of exotics. are few major challenges for fishery scientists for sustaining the native fishes. The other concerns are related to fisheries resource use. All forms of resource-use based on unscientific principles generate enormous wastes and if not mitigated can lead to non-sustainability of the resources. In order to suitably manage the ecosystem for sustainability of fishes in a geographic region, it is essential to know the fish diversity and factors causing loss to the fish diversity. Thus, it is necessary that each geographical region should have account on the fish diversity. The freshwater fishes from Central India have been reported by several workers from their surveys and notable are Hora and Nair (1941), Motwani and David (1957), Dubey and Mehra (1959), Dubey and Verma (1965), Karamchandani et al. (1967), Karmakar and Dutta (1988), Saxena and Srivastava (1989), Rao et al. (1991) and Desai and Srivastava (1997). Until date, no sincere effort has been made to compile such widely dispersed information available in the published literatures. Only a few notable workers such as Ramakrishna et al. (2006), Lakra and Sarkar (2007) and Heda (2009), through their compilation attempted to present the freshwater fish diversity of this region. After 2009, hardly any such effort was made to present the updated information on freshwater fish diversity of this region. Database being essential part of the biodiversity science, is one of the data storage technological concepts for management of natural bioresources of the world in a logical way based on scientific principles. The database technology has been used widely in plants and agriculture research to store information such as gene information (Huala et al., 2001), morphological description (Villordon et al., 2007), growth data (Psomas, et al., 2012) and karyological data (Nagpure et al., 2016).
Nowadays, the modern relational database technologies such as MS Access, MySQL, SQL Server and Oracle provide reasonable approaches to address the natural bioresource problems of multidimensional complexity and allow for efficient search and retrieval of information. Thus, in the present study, focus was given to develop a database by compiling the information on freshwater fish diversity of Central India with special reference to Madhya Pradesh, Rajasthan and Chhattisgarh and digitising the same for information-oriented services. To develop the database, data was collected from the published sources, screened, curated and organised into a database created using MS Access relational database management system. To provide facility for working with the database using user interactive interfaces and tools, Visual Basic technology was used under the Windows operating platform. Presently, the database covers 208 species of fishes belonging to 13 orders, 35 families and 82 genera from Madhya Pradesh, 155 species belonging to 11 orders, 30 families and 81 genera from Rajasthan and 144 species belonging to 11 orders, 30 families and 85 genera reported from Chhattisgarh. The database with integrated tools provide ability to retrieve and view the information of interest. This database uses less computer resources and can easily be deployed as an application package on any portable secondary storage device like CD-ROM, DVD-ROM/RW, portable hard disk and pen drive. Such secondary storage devices can be used to deploy the complete application system with the database on any Intel $x 86$ or later machine. The aim of using MS Access and Visual Basic technologies was to develop a cheaper resource which could easily be distributed among the fisheries workers and worked on a machine that uses less hardware and software resources.

\section{Materials and methods}

\section{Data collection}

To design the database, only published sources like books and journals, both offline and online were used for collecting data on freshwater fishes of the states of Central India with special reference to Madhya Pradesh, Rajasthan and Chhattisgarh. Based on the information published in literatures, the parameters were finalised for collecting the data. Data on taxonomy, synonyms, common name, distribution, economic importance, morphology, colouration, fin formula, habitat and threatened status were collected. In addition to these, photographs of fishes were also collected from the digital library of the photograph of fishes prepared by capturing images of fishes during survey and sampling under different research projects of ICAR-NBFGR, Lucknow.

Published literature surveyed for data collection included: Hora and Menon (1949), Motwani and David 
(1957), Krishna and Menon (1958), Dubey and Mehra (1962), Moona (1963), Dhawan (1969), Mathur and Yazdani (1973), Gupta (1975), Johal and Dhillon (1981), Sharma and Johal (1982), Karmakar and Dutta (1988), Kumar and Asthana (1993), Dubey (1994), Yazdani (1996), Meena and Saxsena (1997), Qureshi (2003), Rathore (2004), Ramakrishna et al. (2006), Dubey (2007), Lakra and Sarkar (2007), Qureshi (2007), Sarkar and Lakra (2007), Heda (2009), Vyas et al. (2009; 2012), Mohan and Ramkishor (2013) and Vishwakarma and Vyas (2014). The collected data was curated and digitised in the different worksheets using Microsoft Excel software.

\section{Database development}

\section{Design of the database structure}

To organise the data in MS Access relational database management system, the different excel worksheets designed under Microsoft Excel software were imported in MS Access. Each imported excel sheet in MS Access created a table, which was renamed and the design of the table was modified, according to the scheme of the database designed using the entity-relationship model proposed by Pin-Shan Chen Peter (1976). This entity-relationship model is developed to graphically represent the logical relationship of entities before creating the design of the database. The records in each table were checked to ensure the data quality. The exported data in MS Access was arranged into six tables namely 'master', 'common name', 'fish reference', 'fish synonym', 'river' and 'state'. The 'fish_id' is the primary key in the master table and foreign key in the remaining five tables. The association between the tables was done using the super, primary and foreign keys. The association defines the relationship and the entities in the database that are one-to-one, one-to-many and many-to-one relationship. The tables include single-value, multi value and composite attribute types. Degree 2 and Degree 3 type of relationship were created between the entities to design the database. Fig. 1 shows the architecture of the database application.

\section{Development of data entry and control interfaces}

In order to maintain the privacy as well as security of the database, a data entry interface logically connected with the database was designed using Visual Basic programming technique that includes the different user interactive windows components. This interface facilitates easy entry of data in the tables of the database conveniently by the user. To facilitate access of information from the database, the user interactive data control interfaces integrated with different windows components like drop down list box, combo box and action command button were designed using the above said technique that facilitate search in and query the database.

\section{Testing and implementation}

For implementing the database, the test cases and test scenarios were prepared in parallel to the design of the database application after discussion with fisheries experts. After writing over the test cases, these were shared with the development team to make sure that development which has happened or happening is satisfying the written test cases. All the test cases were reviewed from angles like requirement coverage, spelling, grammar, test case writing

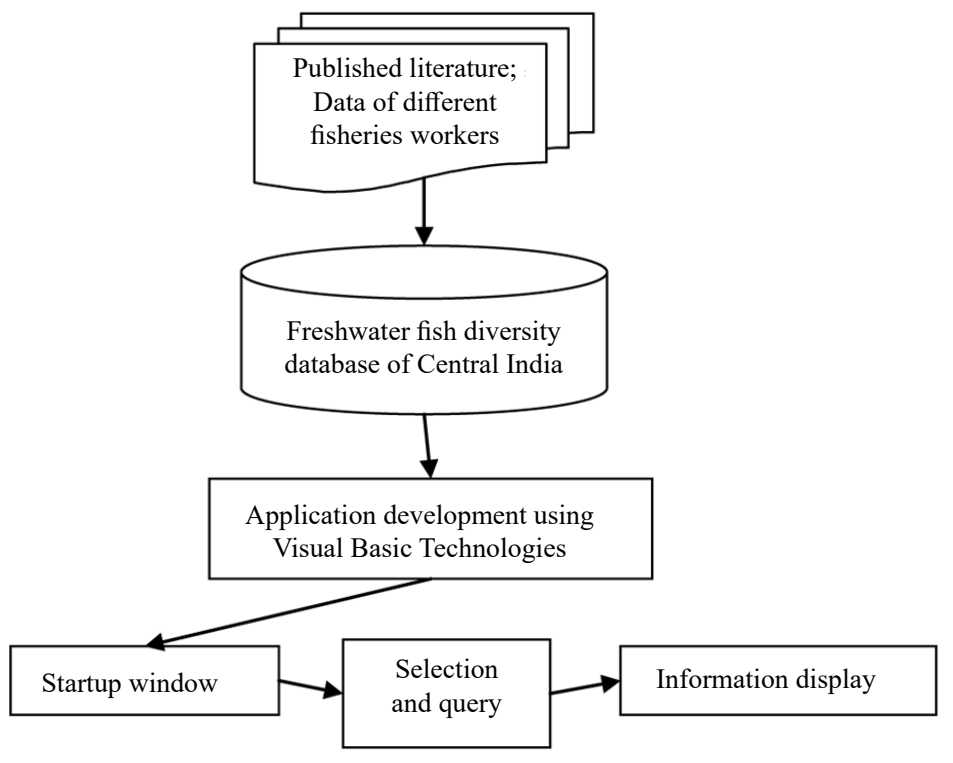

Fig. 1. Architecture of the freshwater fish diversity database application of Central India 
standards, backward compatibility, platform compatibility, test data references and types of targeted testing (manual functional, performance, platform compatibility, usability, security, multi-tenancy). During the testing phase, the important tasks performed were exploratory testing and execution of written test cases, logging defects/bugs, resolving defects/bugs on priority, taking of new code on environment on which testing is happening, marking and verification of defects/bugs. After successful testing of the application, the database with application program was converted into a package for successful installation and working.

\section{Results}

\section{Content analysis}

The database covers 208 species of fishes reported from Madhya Pradesh, 155 from Rajasthan and 144 from Chhattisgarh. All the fish species of these states were documented in the database after curating and checking the synonyms of each fish species from the available resources. Presently, the database provides the information on taxonomy, synonyms, common name, distribution, economic importance, distribution, morphology, colouration, fin formula, habitat and threatened status.

A systematics analysis on systematics account of the fishes covered in the database reported from Madhya Pradesh, Rajasthan and Chhattisgarh was done. Fig. 2

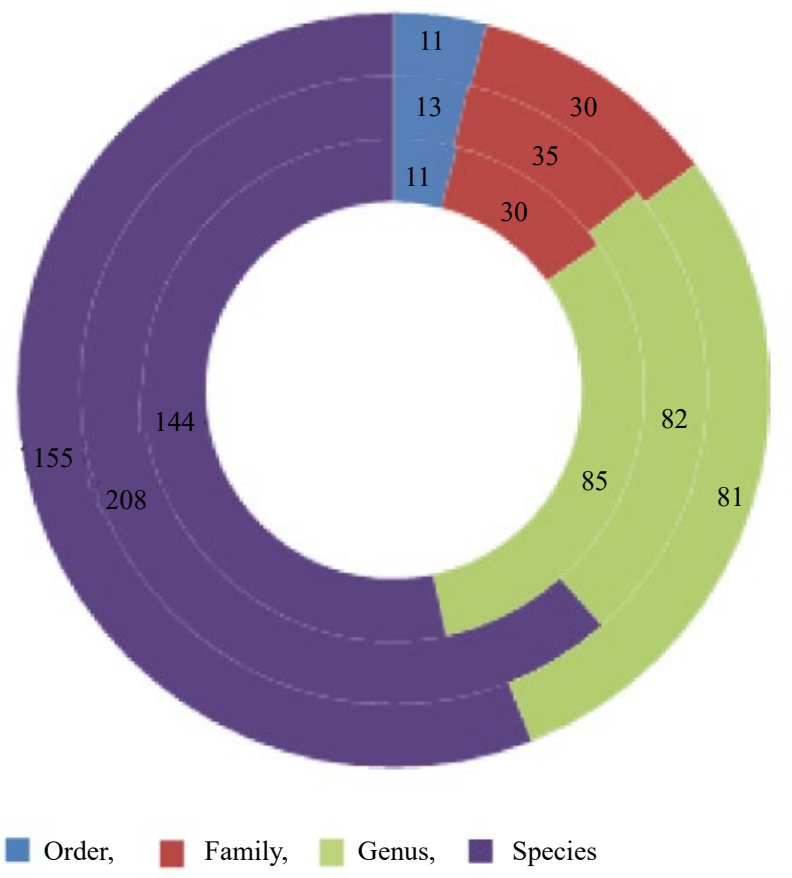

Fig. 2. Systematic view of fishes covered in the freshwater fish diversity database presents an account on the systematics details of fishes covered in the database. The inner most circle represents Chhattisgarh and the outermost Rajasthan. An analysis of the records covered in the four tables viz. Master, Fish_synonyms, Fish_reference and Common_names are presented in Figs. 3, 4 and 5.

Further, an analysis on common fishes between the states showed 130 fish species common between Chhattisgarh and Madhya Pradesh; 104 species common between Chhattisgarh and Rajasthan and 120 species found common between Madhya Pradesh and Rajasthan.

\section{Access of the database}

\section{Deployment and installation}

The database was developed under the Windows operating platform that can easily be stored as an

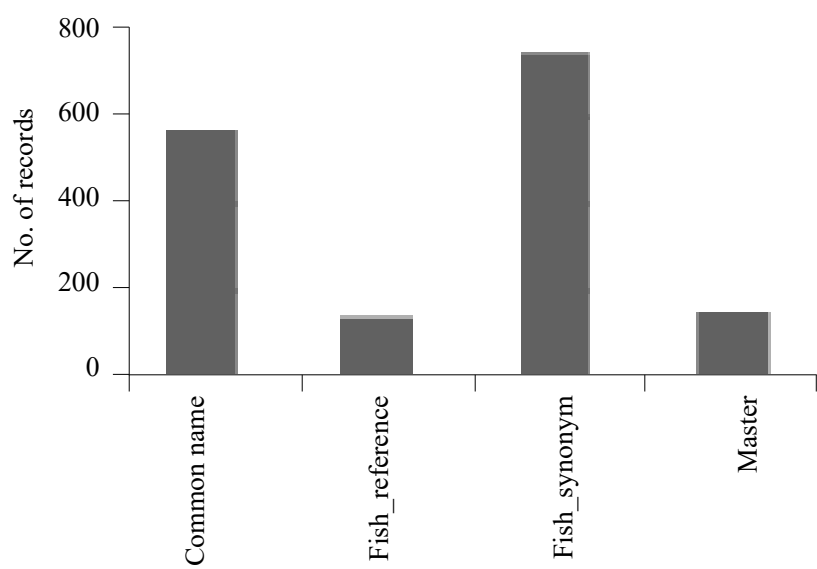

Fig. 3. Content analysis of records in Common name, Fish_reference, Fish_synonym and Master table for Chhattishgarh

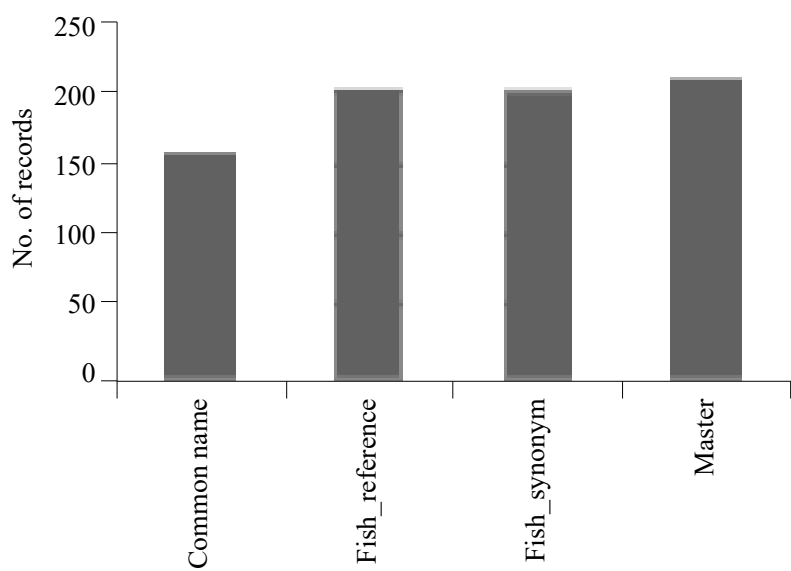

Fig. 4. Content analysis of records in Common name, Fish reference, Fish_synonym and Master table for Madhya Pradesh 


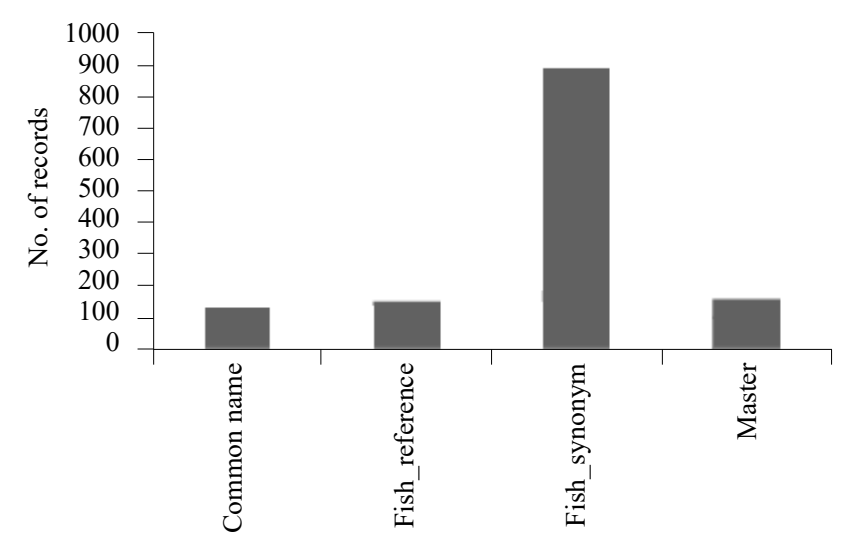

Fig. 5. Content analysis of records in Common name, Fish reference, Fish_synonym and Master table for Rajasthan

application package on any portable secondary storage device like CD-ROM, DVD-ROM/RW, portable hard disk and pen drive. Such secondary storage devices can be used to deploy and install the database application on any Intel x86 or later machines. The system can be installed and made functional using the setup installation wizard after invoking the application package stored on the storage device. After installation, a shortcut icon appears on the desktop screen of the computer, which facilitates working with the database by opening the application. The setup installation wizard installs the program in the program folder of the computer system along with the database stored in the folder named 'Central India Fishes' at the local hard drive. Fig. 6 shows the startup screen of the database.

\section{Utility tools}

To provide access and to work with the database, utility tools were included to search in and query the database. These tools are windows components like drop down list boxes, combo boxes, radio buttons and action command button that provide easy and interactive navigation for querying the database. The startup screen of the database provides the option of selecting the state of interest from the drop down list box for knowing the freshwater fish diversity of that state. Suppose, a user is interested in knowing the freshwater fish diversity of Chhattisgarh State, he/she has to firstly select the Chhattisgarh State from the drop down list box (Fig. 6). This selection opens up a window on the screen (Fig. 7) that provides choices to the user to go ahead or exit from the application. If the user wants to continue with the application, he/she has to click on the 'Next' action command button using mouse that again opens up a window on the screen. This window provides the choices to the user to know about the fish by clicking on either of the action command button labeled

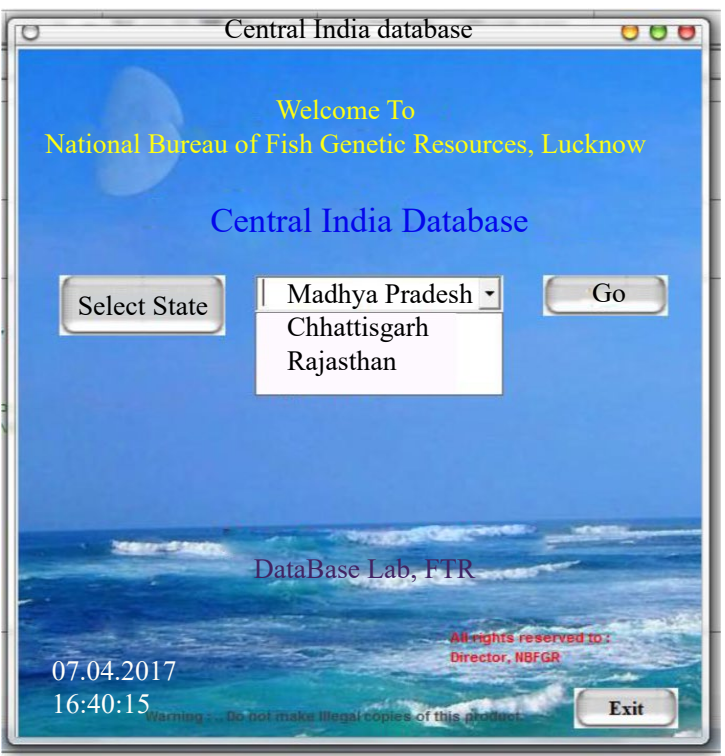

Fig. 6. Startup screen of the database

with 'Scientific name', 'Common name', 'Synonym' and 'References' (Fig. 8). If the user wishes to know the fish details by scientific name, the user has to click on the 'Scientific name' action command button, which again opens up a window on the screen, where the user can select the scientific name of the fish species of interest to know the details with picture. Suppose, a user selects Mystus cavasius in the drop down list box of species name (Fig. 9), the result is presented in the same window (Fig. 9) that includes again action command buttons. The

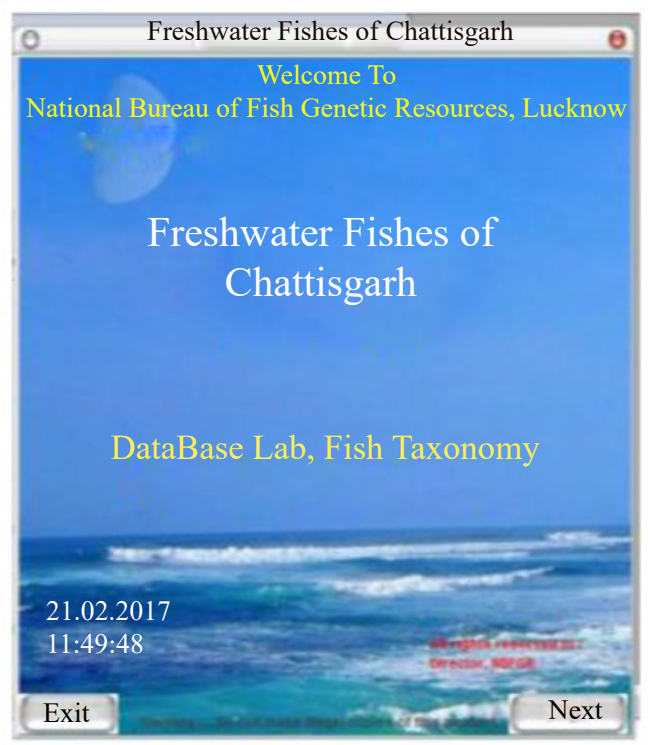

Fig. 7. Screen showing the access to fish diversity information of Chhattisgarh State 


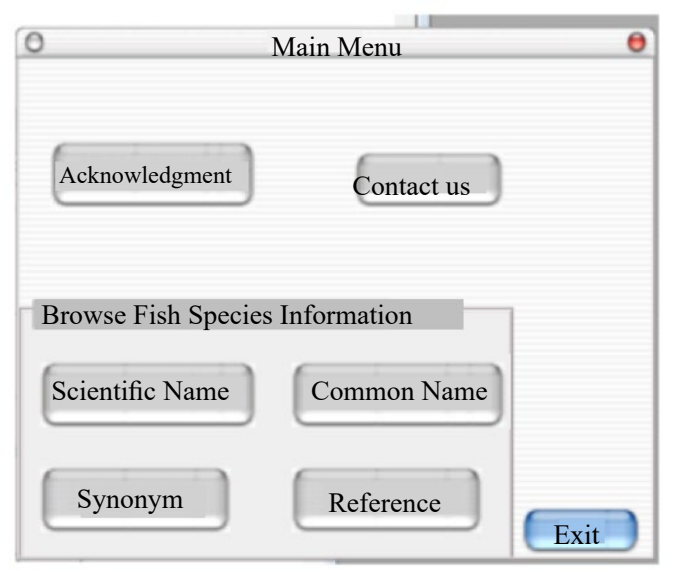

Fig. 8. Screen presenting action command buttons to browse the information from the database

activation of these command buttons provide information about the species on other parameters such as synonyms and references. or to perform some action. The 'Refresh' action command button refreshes the earlier values in the form. The 'Print Form' action command button generates the PDF format of the onscreen result, which can be used by a user for printing. The 'Main menu' action command button brings back the user to the startup screen and the 'Exit' action command button terminates the application. Similar steps can be used to know about the fishes of Madhya Pradesh and Rajasthan.

\section{Discussion}

In India, freshwater fish diversity is declining at an alarming rate. Very few studies are available regarding the threatened status of fishes (Lakra et al., 2010). To support such studies, it is necessary to record the spatial and temporal information on the fish diversity, which is possible effortlessly, if such information is digitised and organised in a database with the option for timely updation. The present database on freshwater fish diversity with special reference to Madhya Pradesh, Rajasthan and Chhattisgarh from Central Plateau region of India is the first database of its kind that covers taxonomy with synonyms and common name, distribution, economic importance, morphology, colouration, fin formula, habitat and threatened status, references and photographs of fishes. After 2009, this is the only updated information resource that present a holistic view on freshwater fish diversity of Central Plateau region of India. Fish being the natural resource, contributes more in the social and economic development of any region and its sustainable management has become the prime concern. To protect biodiversity, ecosystems and wildlife, the sustainable development goal 14 "Life under water" describes fisheries as a major source for global food security, livelihood and economy. Therefore, there is a need to manage fishing sustainably as overfishing can damage fish habitat and weaken the functioning of the ecosystem. This can lead to infringement in the biodiversity with negative repercussions for sustainable social and economic development. Thus, to achieve a healthy balance, it is essential to know about the fishes of that region. The database with its query and data management capability is a targeted technology for digitally documenting and storing large amount of bioresource information in an organised way. Nowadays, this technology is used in every sphere of life and is significant in creating repository resource equipped with facility of searching, retrieving and viewing the information stored. Since, this database stores the freshwater fish diversity information at the population level, the genetic imprinting of various population of lentic fish species is essential as freshwater

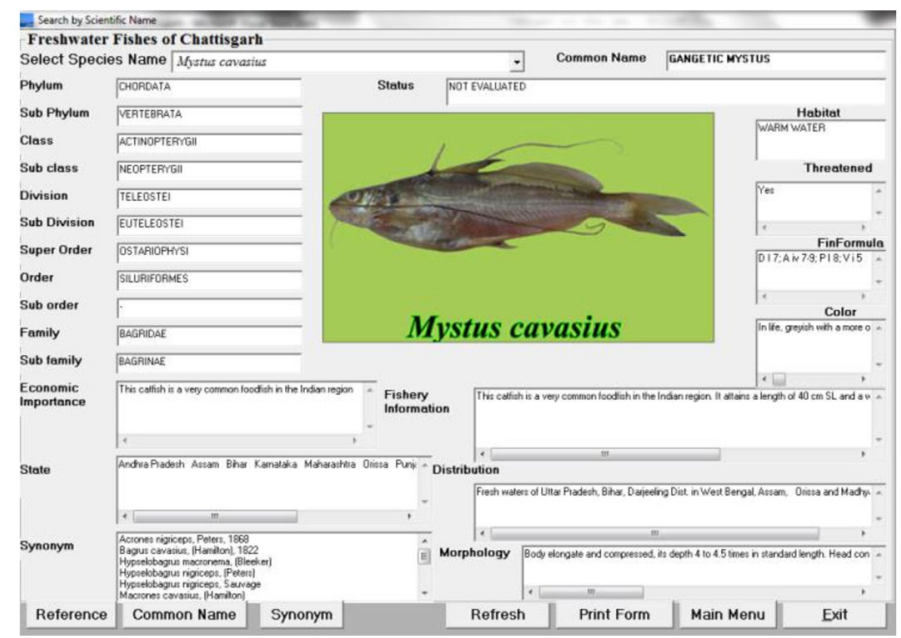

Fig. 9. Display of result after querying the database 
ecosystems constitute crucial parts of their life-support systems by providing nursery grounds and feeding areas (Hammer et al., 1993).

India is one of the signatory nations in the Convention on Biological Diversity (CBD). India is mandated to have inventories and monitor its own bioresources. Unfortunately, freshwater fishes in India have been documented poorly and the Fisheries Act of India of 1897 zeroed exclusively on management of edible fishes. Therefore, it is necessary that the freshwater fishes of this country may be studied in depth not only in terms of identification and classification but also to record their physical, chemical and genetic properties for a better understanding of the ecosystem health and to maintain fishery at sustainable levels. It is also imperative to mention here that FishBase (Froese and Pauly, 2018), which is the widely accessed global biological database on fish does not provide information on fishes reported from the different regions of India like Western Ghats, North-east, Peninsular and Central India . As Central India has diverse water resources that harbour a wide variety of freshwater fishes, it is necessary to know about the freshwater fish diversity of this region in order to save and conserve them in their niche. The database developed under the present study though substantiates this, it lacks a few technological aspects like synchronised data management and concurrent viewing. All necessary cares were taken to maintain the data quality in the database and make the system more user friendly by including the windows interfaces and components.

The freshwater fish diversity database of the Central India region includes the curated and most recent information. The database integrated with utility tools provide ability to search in and query the database for retrieving and viewing the information of interest. This digital documentation of freshwater fish diversity of Central India is a valuable resource for all fisheries stakeholders who have interest in fish diversity. In addition, this can be used as an instrument by the resource managers for fisheries management and exchange of germplasm resources by providing access and benefit to the clientele of this region. Presently, the freshwater fish diversity database of Central India covers 208 species of fishes belonging to 13 orders, 35 families and 82 genera from Madhya Pradesh, 155 species belonging to 11 orders, 30 families and 81 genera from Rajasthan and 144 species belonging to 11 orders, 30 families and 85 genera reported from Chhattisgarh. In future, this database would be upgraded to the web version along with data management capabilities, which will provide ease in managing the data and updating the database regularly.

\section{Acknowledgements}

Authors are thankful to the Director, ICAR-NBFGR, Lucknow for providing the necessary facilities for completing the work.

\section{References}

Baker, A. C., Glynn, P. W. and Riegl, B. 2008. Climate change and coral reef bleaching: An ecological assessment of long-term impacts, recovery trends and future outlook. Estuar. Coast. Shelf Sci., 80(4): 435-471. doi:10.1016/j. ecss.2008.09.003.

Cowx, I. G. 2002. Analysis of threats to freshwater fish conservation, past and present challenges. In: Collares Pereira, M. J., Cowx, I. G. and Coelho, M. M. (Eds.), Conservation of freshwater fishes, options for the future. Blackwell Scientific Press, UK, p. 201-220.

Desai, V. R. and Srivastava, N. P. 1997. Fish fauna of Ravisankar Sagar Reservior. J. Inland Fish. Soc. India, 29(2): 53-56.

Dhawan, S. 1969. Fish fauna of Udaipur lakes. J. Bombay Nat. Hist. Soc., 66: 190-194.

Dubey, G. P. 1994. Endangered, vulnerable and rare fishes of West Coast river system of India. In: Dehadrai, P. V., Das, P. and Verma, S. R. (Eds.), Threatened species of India, Nature Conservators, Muzaffarnagar, India, p.77-95.

Dubey, G. P. 2007. Fish fauna of Madhya Pradesh (1956-2001) and its present status. Fishing Chimes, 26(10): 83-88.

Dubey, G. P. and Mehra, R. K. 1959. Fish and fisheries of Chambal River. Proc. All India Congress Zool., (2): 647-65.

Dubey, G. P. and Mehra, R. K. 1962. Fish and fisheries of Chambal River. Proc. First All-India Congress of Zoology. Part-2, Scientific Papers, The Zoological Society of India, Kolkota, West Bengal, India.

Dubey, G. P. and Verma, M. N. 1965. A preliminary study of the fish fauna of Madhya Pradesh. Vikram Univ. J., 8(4): 52-59.

Froese, R. and Pauly, D. 2018. FishBase. World Wide Web electronic publication. www.fishbase.org, version (02/2018).

Gupta, P. D. 1975. Fifty years (1920-1969) of faunistic survey of Rajasthan (India). Records of the Zoological Survey of India, 68: 383.

Hammer, M., Jansson, A. and Jansson, B. O. 1993. Diversity change and sustainability: Implications for fisheries. Ambio, p. 97-105.

Heda, N. 2009. Freshwater fishes of Central India: A field guide. Vigyan Prasar, New Delhi, India, 169 pp.

Hora, S. L. and Menon, M. A. S. 1949. The fish fauna of the Rihand River and its zoogeographical significance. J. Zool. Soc. India, 1(1): 1-6.

Hora, S. L. and Nair, K. K. 1941. Fishes of Satpura Range, Hoshangabad District, Central Province. Rec. Indian Mus., 43(3): 361-373. 
Huala, E., Dickerman, A. W., Garcia-Hernandez, M., Weems, D., Reiser, L., LaFond, F., Hanley, D., Kiphart, D., Zhuang, M., Huang, W. and Mueller, L. A. 2001. The Arabidopsis Information Resource (TAIR): A comprehensive database and web-based information retrieval, analysis and visualisation system for a model plant. Nucleic Acids Res., 29(1): 102-105. doi: 10.1093/nar/29.1.102.

Johal, M. S. and Dhillon, K. S. 1981. Ichthyofauna of Ganganagar District (Rajasthan) India. Res. Bull. Punjab Univ., 32: 105-110.

Kar, D. and Barbhuiya, M. H. 2004. Abundance and diversity of zooplankton in Chatla Haor, a floodplain wetland in Cachar District of Assam. Environ. Ecol., 22(1): 247-248.

Karamchandani, S. J., Desari, V. R., Pisolkar, M. D. and Bhatnagar, G. K. 1967. Biological investigations on the fish and fisheries of Narmada River (1958-1966). Bulletin of the Central Inland Fisheries Research Institute, vol. 10. ICAR-Central Inland Fisheries Research Institute, Barrackpore, India, p. 1-39.

Karmakar, A. K. and Dutta, A. K. 1988. On a collection of fishes from Bastar District, Madhya Pradesh. Rec. Zool. Surv. India, Occ. Paper No. 98. The Zoological Survey of India.

Krishna, D. and Menon, C. B. 1958. A note on the fishes of Jodhpur (Rajasthan). Vijnana Parishad Anusandhan Patrika, 1(4): 207-209.

Kumar, C. A. and Asthana, A. R. U. N. 1993. The fish fauna of Rajasthan. Indian Rev. Life Sci., 13: 133-148.

Lakra, W. S. and Sarkar, U. K. 2007. Freshwater fish diversity of Central India. Proceedings, Conservation assessment of freshwater fish diversity for Central India. ICAR-National Bureau of Fish Genetic Resources, Lucknow, Uttar Pradesh, India.

Lakra, W. S., Sarkar, U. K., Gopalakrishnana, A. and Khatirvelpandian, A. 2010. Threatened freshwater fishes of India. ICAR-National Bureau of Fish Genetic Resources, Lucknow, Uttar Pradesh, India.

Mathur, D. S. and Yazdani, G. M. 1973. Additional record of the fish from Jodhpur with a list of species occurring in the district. Sci. Cult. Calcutta, 39: 87-89.

Meena, D. and Saxsena, G. 1997. Fisheries resources and fish fauna of district Bhopal (MP). Res. J. Social Life Sci., 129 pp.

Mohan, D. and Ramkishor 2013. Ichthyofauna of Rajasthan. In: Sharma, B., Kulshreshtha, S. and Rahmani A. (Eds.), Faunal heritage of Rajasthan, India. Springer, New York, USA.

Moona, J. C. 1963. Notes on fishes from Bharatpur District, Rajasthan. Rec Indian Mus., 58(2): 59-66.

Motwani, M. P. and David, A. 1957. Fishes of the river Sone with observations of the zoogeographical significance. Zool. Soc. India, 9(1): 9-15.

Nagpure, N. S., Pathak, A. K., Pati, R., Rashid, I., Sharma, J., Singh, S. P., Singh, M., Sarkar, U. K., Kushwaha, B., Kumar, R. and Murali, S., 2016. Fish Karyome version
2.1: A chromosome database of fishes and other aquatic organisms. Database, 2016, p.baw012.

NBFGR 2020. Annual report 2020, ICAR-National Bureau of Fish Genetic Resources, Lucknow, Uttar Pradesh, India, $160 \mathrm{pp}$.

Pin-Shan Chen Peter 1976. The Entity-Relationship ModelToward a unified view of data. ACM Transactions on Database Systems, 1(1): 9-36.

Psomas, A. N., George-John Nychas, Serkos A. Haroutounian and Panagiotis Skandamis 2012. LabBase: Development and validation of an innovative food microbial growth responses database. Computers and Electronics in Agriculture, 85: 99-108.

Qureshi, T. A. 2003. Status of finfish diversity of Madhya Pradesh. In: Lakra, W. S. and Sarkar, U. K. (Eds.), Freshwater fish diversity of Central India. ICAR-National Bureau of Fish Genetic Resources, Lucknow, India, p. 35-41.

Qureshi, T. A. 2007. Status of finfish diversity of Madhya Pradesh. Proceedings of the Workshop on Conservation assessment of freshwater fish diversity for Central India, p. 07-18.

Ramakrishna, Chandra, K., Nema Ahirwar and Alfred, J. R. B. 2006. Faunal resources of National parks of Madhya Pradesh and Chhattisgarh. Conservation Area Series, 30: $1-123+27$.

Rao, K. S., Chatterjee, S. N. and Singh, A. K. 1991. Studies on preimpoundment fishery potential of Narmada Basin (west region). J. Inland Fish. Soc. India, 23(1): 34-41.

Rathore, N. 2004. Desert National Park - An overview on fauna of desert national park, Rajasthan. Proposed Biosphere Reserve, Zoological Survey of India, 19: 135 pp.

Sala, O. E., Chapin, F. S., Armesto, J. J., Berlow, R., Bloomfield, J., Dirzo, R., Huber-Sanwald, E., Huenneke, L. F., Jackson, R. B., Kinzig, A., Leemans, R., Lodge, D., Mooney, H. A., Oesterheld, M., Poff, N. L., Sykes, M. T., Walker, B. H., Walker, M. and Wall, D. H. 2000. Global biodiversity scenarios for the year 2100. Science, 287: 1770-1774.

Sarkar, U. K. and Lakra, W. S. 2007. An overview of the diversity and conservation status of freshwater fishes of Central India. In: Lakra, W. S. and Sarkar, U. K. (Eds.), Freshwater fish diversity of Central India. ICAR-National Bureau of Fish Genetic Resources, Lucknow, India, p. 7-18.

Saxena, R. and Srivastava, P. 1989. A checklist of fish fauna of Kunwari River (tributary of Chambal River), North Madhya Pradesh. J. Inland Fish. Soc. India, 21(2): 41-44.

Sharma, K. P. and Johal, M. S. 1982. On the fish and fisheries of Jaismund Lake, Rajasthan, India. J. Czechoslovak Zool. Soc. (In Slovak). 
Suski, C. D. and Cooke, S. J. 2006. Conservation of aquatic resources through the use of freshwater protected areas: Opportunities and challenges. Biodivers. Conserv., 17: 2495-2511.

Talwar, P. K. and Jhingran, A. G. 1991. Inland fishes of India and adjacent countries, vol. I and II. Oxford and IBH Publishing Co., New Delhi, India, 1158 pp.

Uchchariya, D. K., Saxena, M. and Saksena, D. N. 2012. Fish biodiversity of Tighra Reservoir of Gwalior, Madhya Pradesh, India. J. Fish. Aquac., 3(1): 37.

Villordon, A., Wambui Njuguna, Simon Gichuki, Philip Ndolo and Don Labonte 2007. Using open source software in developing a web-accessible database of sweet potato germplasm collections in Kenya. Hortic. Technol., 17(4): 567-570.
Vishwakarma, K. S. and Vyas, V. 2014. Study on species diversity and assemblage of fish fauna of Jamner River: A tributary of river Narmada. Int. J. Appl. Biosci., 2(3): 134-141.

Vyas, V., Damde, D. and Parashar, V. 2009. Fish diversity of Narmada in submergence area of Indra Sagar Reservoir. J. Inland Fish. Soc. India, 41(2): 18-25.

Vyas, V., Damde, D. and Parashar, V. 2012. Fish biodiversity of Betwa River in Madhya Pradesh, India with special reference to a sacred ghat. Int. J. Biodivers. Conserv., 4(2): 71-77.

Yazdani, G. M. 1996. Fish diversity in the Thar Desert. In: Faunal diversity in the Thar Desert: Gaps in research. Scientific Publishers, Jodhpur, India, p. 285-295. 